\title{
CONVECTIVE HEAT TRANSFER AND FULLY DEVELOPED FLOW FOR CIRCULAR TUBE NEWTONIAN AND NON-NEWTONIAN FLUIDS CONDITION
}

\author{
Ahmed Jassim Shkarah ${ }^{1, *}$
}

\begin{abstract}
We represent a conceptual scrutiny for completely organized convective heat transfer ring within the circular pipeline with power law liquids by means of realizing that the heat diffusivity has been a temperature gradient. The investigative resolution is availed and the behaviour of the heat transfer is inspected under a persistent thermic flux frontier condition. It has been demonstrated that the Nu stubbornly relies upon the power-law index $\mathrm{n}$ value. The $\mathrm{Nu}$ (Nusselt number) recognizably gets reduced in a range of $\mathrm{n}$ from 0 to 0.1 . Nonetheless, for $\mathrm{n}$ greater than 0.5 , there is a monotonic decrement in the $\mathrm{Nu}$ with the incremental $\mathrm{n}$, and for $\mathrm{n}$ greater than 20 , values of the $\mathrm{Nu}$ have approached a constant.
\end{abstract}

\section{Keywords: Non-Newtonian Fluids, Convective Heat Transfer}

\section{INTRODUCTION}

In recent time, weighable attention has been drawn by the shortcoming of how foresee a behavioural flow of heat transfer for non-Newtonian liquids. The key ground for this is perhaps that liquids (like slurries, molten plastics, emulsions, pulps, etc.) that do not abide by Newtonian, hypothesize that the stress-tensor is straightforwardly proportionate to the deformation-tensor, are gained industry-wise enhanced quantities and have been therefore, on a few occasions, simply as plausible to just get impelled in a plant as generic Newtonian liquids. Scholars have been striving for establishing a mathematical form so as to determine the connection between the deformation and stress and heat transfer appropriate to non-Newtonian liquids [1-4]. Howell et al. [5] and Barletta et al. [2] have experimented the heat transfer and momentum on a ceaseless poignant surface in relation with the power-law liquids. Many authors [6-9] have made analysis on the mixed convection typed heat transfer using a horizontal or vertical plate for a liquid, which is non-Newtonian; with homogeneous heat flux of the surface. Hussanien et al. [10] inspected on the heat transfer within a power-law liquid over a Non-isothermal widened sheet. According to Kumari et al.[11], the convection-free flow at border-layer of non-Newtonian liquid, the length of a vertical surface remains wavy. Huang and $\mathrm{Li}$ [12] emphasized on the completely organized convective heat transfer ring within a pipeline for a non-Newtonian liquid, the arithmetical models had been set up for power-law liquid, the Bingham liquid and Carson liquid, and the resolutions had been represented respectively. For the prime references that belong to the huge literature of this subject matter in non-Newtonian liquids, for example $[4,11$ 15]. In above mentioned works that were cited, the power-law kinematic glueyness had been implemented solely to the momentum equations, while the conductivity based on heating, $\mathrm{k}$ yet seems to be constant. This is seemingly contradictory because of the fact that the glueyness change is very likely to affect both the thermic equations and the momentum. Throughout the whole letter, within a pipeline, a fully organized power-law non-Newtonian liquidbased convectional heat transfer has been measured by us.

\section{MATHEMATICAL MODELLING}

We have proposed a thermic-centric equation replica by bearing the power-law kinematic glueyness effects in mind and then provide the similarity resolution. For an uncompressed power-law non-Newtonian liquid in cylinder-based organizes systems, its stress of shear has been typified as:

$$
\tau=K\left(\left|\frac{\partial u}{\partial r}\right|^{n-1} \frac{\partial u}{\partial r}\right)
$$

and kinematic glueyness is

This paper was recommended for publication in revised form by Regional Editor Baha Zafer

${ }^{1}$ Department of Mechanical Engineering, University of Thi-Qar, Iraq

*E-mail address: ahmedshkara@gmail.com, shkarah@utq.edu.iq

Orcid id: 0000-0001-9762-3201

Manuscript Received 4 March 2019, Accepted 1 June 2019 


$$
v=\gamma\left|\frac{\partial u}{\partial r}\right|^{n-1}
$$

$\mathrm{n}=1$, this case keeps up a correspondence to a piece of Newtonian liquid and $0<\mathrm{n}<1$, this case has been the power-law relationship proposed like getting depictive of pseudo-plastic non-Newtonian liquids and $n>1$, this case depicts the dilatants liquid $[5,10,14,16-20]$.

The continuality equation as well as the equations of momentum in the circumferential and radial directions becomes mislaid and the equation of momentum in flow is likely to get simplified into

$$
\frac{1}{r} \frac{d}{d r}\left(r \tau_{r x}\right)-\frac{d p}{d x}=0
$$

with boundary condition:

$$
\begin{array}{lll}
\frac{d u}{d t}=0 & \text { at } & r=0 \\
u=0 & \text { at } & r=R
\end{array}
$$

The coupled Eq. (3) with boundary conditions are availed to be [21]

$$
u=u_{m} \frac{1+3 n}{1+n}\left(1-\left(\frac{r}{R}\right)^{\frac{1+n}{n}}\right)
$$

and $u_{m}=\frac{Q}{\pi r^{2}}$

The heat transformed in each unit surface zone and each unit time has been surmised by the vector of heat flux $\mathrm{q}$ $\left(\mathrm{q}_{\mathrm{x}}, \mathrm{q}_{\mathrm{y}}, \mathrm{q}_{\mathrm{z}}\right)\left(\mathrm{J} / \mathrm{m}^{2} \mathrm{~s}\right)$, specified thermal capability of the isobar is surmised by $c_{\mathrm{p}}$, furthermore, the condensation ratio is surmised by $\rho$. Applying Fourier's equation of heat, that can be get the following:

$$
q=-k \nabla T
$$

This equation interprets the molecular transmission of heat to be in isotropic. For little amount of temperature gradient, thermal conductivity is nominally utilized as an invariable, where for big temperature gradient, thermal conductivity has been a relational functioning with the temperature

$$
K=K(T)
$$

The dissipation's function is:

$$
\Phi=\nabla(\tau v)-v \nabla(\tau)
$$

with:

$$
h=\frac{p}{\rho}+e
$$

and:

$$
\rho=\frac{d h}{d t}=-\nabla q+\phi+\frac{d p}{d t}
$$

Finally, the energy equation is: 


$$
\rho c_{p} \frac{d T}{d t} \nabla\left(k(T)+\beta T \frac{d p}{d t}+\phi=0\right.
$$

It has been presumed that the heat has been relocated to the flow region using the surrounding walls, therefore a thermal zone creates together with the speed, and the region of temperature has a speed zone character as well at the top Reynolds numbers. As an instance, we have implemented this presumption to the fully developed convectional heat transfer. On this occasion, by bearing the power-law glueyness effects and the equivalence between the thermal zone and velocity zone in mind, the thermal conductivity can be elected a form:

$$
k(T)=k\left|\frac{\partial T}{\partial r}\right|^{n-1}
$$

along with $\mathrm{k}$ to be a positive invariable.

and:

$$
q=-k\left|\frac{\partial T}{\partial r}\right|^{n-1} \frac{\partial T}{\partial r}
$$

Then, in the nonexistence of the body effect, exterior pressure gradients as well as gluey indulgence, the thermic equation conveying energy conservation for the fully developed convectional heat transfer within a circular pipeline becomes able to be written as

$$
u \frac{\partial T}{\partial x}=\frac{1}{\rho c_{p}} \frac{\partial}{r \partial r}\left(r k(T) \frac{\partial T}{\partial r}\right)
$$

with:

$$
\frac{\partial T}{\partial r}=0 \rightarrow r=0
$$

for constant wall temperature:

$$
T=T_{w} \rightarrow r=R
$$

with dimensionless form:

$$
\varphi=\frac{T-T_{w}}{T_{m}-T_{w}}
$$

But $\frac{\partial \varphi}{\partial x}=0$ for fully developed flow in tube, so Eq. (17) become:

$$
T=T_{w}+\varphi\left(T_{m}-T_{w}\right)
$$

and then for constant wall temperature:

$$
\frac{\partial T}{\partial x}=\varphi \frac{d T_{m}}{d x}
$$

We can define the mean temperature as:

$$
T_{m}=\frac{2}{R^{2} u_{m}} \int_{0}^{R} r u T d r
$$

for heat flux: 


$$
q_{w}=-k\left|\frac{\partial T}{\partial r}\right|_{w}^{n-1}\left(\frac{\partial T}{\partial r}\right)_{w}
$$

Then we get:

$$
q_{w}=k_{0}\left|T_{m}-T_{w}\right|^{n-1}\left(T_{m}-T_{w}\right)\left|\frac{\partial \varphi}{\partial r}\right|_{w}^{n-1}\left(\frac{\partial \varphi}{\partial r}\right)_{w}
$$

By solving $\mathrm{Eq}(14)$ with $\mathrm{Eq}(5), \mathrm{Eq}(19)$ and $\mathrm{Eq}(12)$ we can get :

$u_{m} \frac{1+3 n}{1+n}\left(1-\left(\frac{r}{R}\right)^{\frac{1+n}{n}}\right)\left(\frac{T-T_{w}}{T_{m}-T_{w}}\right) \frac{d T_{m}}{d x}=\frac{1}{\rho c_{p}} \frac{\partial}{r \partial}\left(r\left|\frac{\partial T}{\partial r}\right|^{1+n} \frac{\partial T}{\partial r}\right)=\frac{k}{\rho c_{p}} \frac{\partial}{r \partial r}\left(r\left|\frac{\partial T}{\partial r}\right|^{n-1} \frac{\partial T}{\partial r}\right)$

with boundary conditions:

$$
\begin{aligned}
& r=0 \rightarrow \frac{\partial T}{\partial r}=0 \\
& r=R \rightarrow T=T_{w}
\end{aligned}
$$

We integrate Eq. (23) by applying boundary conditions on Eq. (24) and for special case for $n=1$ we can find the Temperature profile as fully developed flow and heat transfer:

$$
T(r)=\frac{-20 u_{m} R^{4}+6 u_{m} \frac{d T_{m}}{d x} R^{4}+20 u_{m} R r^{3}-\frac{6 u_{m} \frac{d T_{m}}{d x} r^{5}}{R}+60 k R T_{w}}{60 k R}
$$

For Nusselt number:

$$
N u=\frac{2(1+n)^{2}}{n(1+3 n) \int_{0}^{1}\left[\left(\frac{1+3 n}{1+n}\right)^{1+\frac{1}{n}}\left(1-\frac{2 n}{1+3 n}\right) \varsigma^{1+\frac{1}{n}}-1\right]\left(1-\varsigma^{1+\frac{1}{n}}\right) \varsigma d \varsigma}
$$

where $\varsigma=\frac{y}{b}$

We solve Eq. (26) numerically as on table 1

Table 1. Nusselt number

\begin{tabular}{|c|c|}
\hline $\boldsymbol{n}$ & $\boldsymbol{N u}$ \\
\hline 0.001 & 633.333 \\
\hline 0.01 & 65.877 \\
\hline 0.05 & 15.787 \\
\hline 0.1 & 9.59 \\
\hline 1.0 & 4.565 \\
\hline 1.4 & 4.234 \\
\hline 1.9 & 4.176 \\
\hline 5.0 & 4.058 \\
\hline
\end{tabular}




\section{RESULTS \& DISCUSSION}

It is familiar to us that for fully developed convectional heat transfer for Newtonian liquid, The $\mathrm{Nu}$ becomes an invariable, $\mathrm{Nu} \approx 4.464$ for invariable heat flux $\mathrm{q}=\mathrm{q}_{\mathrm{w}}$. Nonetheless, for a power-law non-Newtonian liquid, the common Nu becomes a power-law index function and at the same time it is stubbornly reliant upon the value of $\mathrm{n}$. Table 1 signifies that $\mathrm{Nu}$ has been a lessening function of $\mathrm{n}$. We find it to be clear that $\mathrm{Nu}$ has a sharp decrement in the range of $0<\mathrm{n}<1$. Nevertheless, for $\mathrm{n}>0.5$, Nu gets reduced monotonically with increased $\mathrm{n}$ and in appropriation with the power-law index, $\mathrm{n} \geq 20$, the Nu value has approached an invariable, which is asymptotic as in Figure 1.

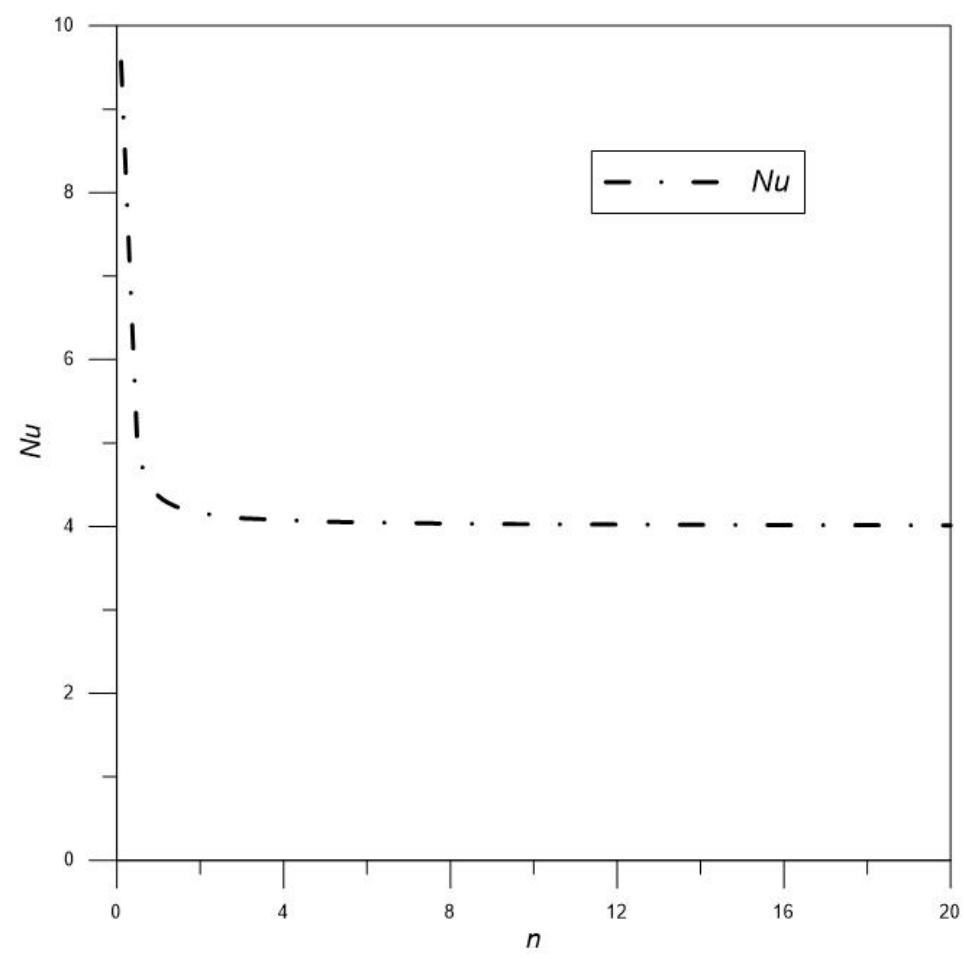

Figure 1. Nusselt number with $n$

\section{CONCLUSION}

The issue of constrained convection in regards to the Heat transfer, with gluey dissemination inside a pipeline, which subjects to determined divider temperature, is settled scientifically that has been a sort of Graetz issue. Full diagnostic goals for the fluid temperature just as nearby $\mathrm{Nu}$ (Nusselt number) have been profited. The effect of the $\mathrm{Br}$ and the rheological power-law list (properties) upon nearby $\mathrm{Nu}$ profile are exhibited through numerical measurements. The neighbourhood $\mathrm{Nu}$ in heat zone is going to develop with a decrement in a list of intensity law reproduction (n). It uncovered the gluey dispersal inside a fluid is probably going to surprisingly make sway on laminar flow heat transfer.

\section{NOMENCLATURE}

$\mathrm{C}_{\mathrm{p}}$

$\mathrm{h}$

$\mathrm{n}$

$\mathrm{Nu}$

$\mathrm{r}$

$\mathrm{R}$

$\mathrm{T}$

u

$\mathrm{u}_{\mathrm{m}}$

$\mathrm{q}_{\mathrm{w}}$ specific heat

local heat transfer coefficient

power-law model parameter

local Nusselt number

radial coordinate

pipe radius

fluid temperature $(\mathrm{K})$

axial fluid velocity $(\mathrm{m} / \mathrm{s})$

mean axial fluid velocity $(\mathrm{m} / \mathrm{s})$

constant heat flux 


\section{REFERENCES}

[1] Acrivos A., S., M.J. and Petersen, Momentum and Heat Transfer in Laminar Boundary Layer Flows of Non-Newtonian Fluids Past External Surfaces. AIChE Journal, 1960. 6: p. 312-317.

[2] Barletta, A., E.J.I.j.o.h. Zanchini, and m. transfer, Forced convection in the thermal entrance region of a circular duct with slug flow and viscous dissipation. 1997. 40(5): p. 1181-1190.

[3] Dang, V.-D.J.J.o.h.t., Heat transfer of power law fluid at low peclet number flow. 1983. 105(3): p. 542549.

[4] Eckert, E.R.G. and R.M. Drake Jr, Analysis of heat and mass transfer. 1987.

[5] Howell, T.G., D.R. Jeng, and K.J. De Witt, Momentum and heat transfer on a continuous moving surface in a power law fluid. International Journal of Heat and Mass Transfer, 1997. 40(8): p. 1853-1861.

[6] Rohsenow, W.M., J.P. Hartnett, and Y.I. Cho, Handbook of heat transfer. Vol. 3. 1998: McGraw-Hill New York.

[7] Wang, T.-Y.J.I.c.i.h. and m. transfer, Mixed convection from a vertical plate to non-Newtonian fluids with uniform surface heat flux. 1995. 22(3): p. 369-380.

[8] Zanchini, E.J.I.j.o.h. and m. transfer, Effect of viscous dissipation on the asymptotic behaviour of laminar forced convection in circular tubes. 1996. 40(1): p. 169-178.

[9] Hady, F.J.A.m. and computation, Mixed convection boundary-layer flow of non-Newtonian fluids on a horizontal plate. 1995. 68(2-3): p. 105-112.

[10] Hassanien, I., et al., Flow and heat transfer in a power-law fluid over a nonisothermal stretching sheet. 1998. 28(9): p. 105-116.

[11]. Kumari, M., et al., Free-convection boundary-layer flow of a non-Newtonian fluid along a vertical wavy surface. 1997. 18(6): p. 625-631.

[12] Wang, Z.-G., et al., Enzyme immobilization on electrospun polymer nanofibers: an overview. 2009. 56(4): p. 189-195.

[13] Aghakhani, S., et al., Numerical investigation of heat transfer in a power-law non-Newtonian fluid in a C-Shaped cavity with magnetic field effect using finite difference lattice Boltzmann method. 2018. 176: p. 5167.

[14] Akbari, O.A., et al., The effect of velocity and dimension of solid nanoparticles on heat transfer in nonNewtonian nanofluid. 2017. 86: p. 68-75.

[15] Brinkman, H.J.A.S.R., Heat effects in capillary flow I. 1951. 2(1): p. 120.

[16] Aydin, O.J.E.C. and management, Effects of viscous dissipation on the heat transfer in forced pipe flow. Part 1: both hydrodynamically and thermally fully developed flow. 2005. 46(5): p. 757-769.

[17] Bergman, T.L., et al., Fundamentals of heat and mass transfer. 2011: John Wiley \& Sons.

[18] Lin, T., K. Hawks, and W.J.W.-u.s. Leidenfrost, Analysis of viscous dissipation effect on thermal entrance heat transfer in laminar pipe flows with convective boundary conditions. 1983. 17(2): p. 97-105.

[19] Liou, C.-T. and F.-S.J.N.h.t. Wang, Solutions to the extended Graetz problem for a power-model fluid with viscous dissipation and different entrance boundary conditions. 1990. 17(1): p. 91-108.

[20] Zheng, L.-C., X.-X. Zhang, and L.-X. Ma, Fully Developed Convective Heat Transfer of Power Law Fluids in a Circular Tube. Chinese Physics Letters, 2008. 25(1): p. 195.

[21] Wang, C. and I.J.J.o.N.-N.F.M. Pop, Analysis of the flow of a power-law fluid film on an unsteady stretching surface by means of homotopy analysis method. 2006. 138(2-3): p. 161-172. 